\title{
Peak Expiratory Flow Time
}

National Cancer Institute

\section{Source}

National Cancer Institute. Peak Expiratory Flow Time. NCI Thesaurus. Code C139259.

The time from the start of the test until the subject reaches his maximum expiratory gas flow rate. 